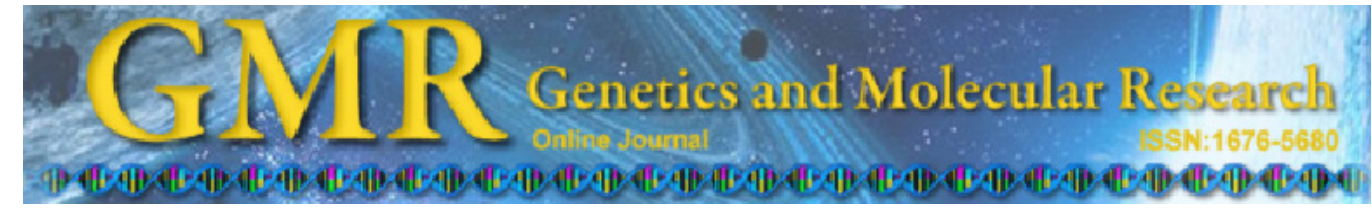

Short Communication

\title{
Microsatellite usefulness is independent of phylogenetic distance in Tyrant flycatchers (Aves: Tyrannidae): a test using two globally threatened species
} J.C. Reboreda ${ }^{1}$ and R. Tiedemann ${ }^{2}$

${ }^{1}$ Departamento de Ecología, Genética y Evolución, Facultad de Ciencias Exactas y Naturales, Universidad de Buenos Aires, Pabellón II Ciudad Universitaria, Buenos Aires, Argentina

${ }^{2}$ Unit of Evolutionary Biology/Systematic Zoology, Institute of Biochemistry and Biology, University of Potsdam, Potsdam-Golm, Germany

${ }^{3}$ Departamento de Conservación, Aves Argentinas/Asociación Ornitológica del Plata, Buenos Aires, Argentina

Corresponding author: B. Mahler

E-mail: bemahler@ege.fcen.uba.ar

Genet. Mol. Res. 12 (3): 2966-2972 (2013)

Received August 22, 2012

Accepted February 22, 2013

Published August 12, 2013

DOI http://dx.doi.org/10.4238/2013.August.12.12

\begin{abstract}
Tyrant flycatchers (Aves: Tyrannidae) are endemic to the New World, and many species of this group are threatened or near-threatened at the global level. The aim of this study was to test the 18 microsatellite markers that have been published for other Tyrant flycatchers in the Strange-tailed Tyrant (Alectrurus risora) and the Sharp-tailed Tyrant (Culicivora caudacuta), two endemic species of southern South American grasslands that are classified as vulnerable. We also analyzed the usefulness of loci in relation to phylogenetic distance to the source species. Amplification success was high in both species
\end{abstract}


( 77 to $83 \%$ ) and did not differ between the more closely and more distantly related species to the source species. Polymorphism success was also similar for both species, with 9 and 8 loci being polymorphic, respectively. An increased phylogenetic distance thus does not gradually lead to allelic or locus dropouts, implying that in Tyrant flycatchers, the published loci are useful independent of species relatedness.

Key words: Alectrurus risora; Culicivora caudacuta; Microsatellites; Tyrannidae

\section{INTRODUCTION}

Tyrant flycatchers (Aves: Tyrannidae) are endemic to the New World, with the highest diversity occurring in the Neotropics. They form one of the most diverse bird families of the world, including 429 recognized species and 104 genera (Fitzpatrick, 2004). Thirteen percent of the species of this group are threatened (10 endangered and 19 vulnerable species) or nearthreatened (27 species) at the global level (Bird Conservation International, 2009). However, most of the population and reproductive parameters for managing these species in both protected and unprotected areas are still not available.

Most of the Tyrant flycatchers are typical forest inhabitants, foraging for arthropods in the foliage or executing aerial sallies from visible perches (Fitzpatrick, 2004). Some of them have, however, diversified towards open habitats, occupying grasslands, steppes, and wetlands along the Andes, Patagonia, and Pampas in western and southern South America (Ohlson et al., 2008). Populations of endemic grassland birds, including Tyrant flycatchers, have declined dramatically over the recent decades in these habitats, where they now exist mostly in isolated fragments scattered in an agricultural matrix (Bird Conservation International, 2009).

Recently, some bird conservation efforts have been directed to identify remaining populations of a set of globally threatened species along the grasslands. Two species that have been recognized as good indicators of sites with natural grasslands containing most complete sets of other endemic and threatened grassland birds were the Strange-tailed Tyrant (Alectrurus risora) and the Sharp-tailed Tyrant (Culicivora caudacuta) (Devenish et al., 2009). The Strange-tailed Tyrant has suffered a large contraction, reaching a $90 \%$ loss of its original range because of associated changes in natural grasslands use during the last century. Further decline in range and number is expected, because suitable habitats are subject to extensive agricultural modification and afforestation (Bird Conservation International, 2009). The Sharp-tailed Tyrant also appears to have undergone a rapid decline due to habitat destruction, with fragmented, mostly rare, and very local populations. Both species are classified as globally vulnerable (Bird Conservation International, 2009).

In this paper, we aimed to study microsatellite markers that have been published for other Tyrant flycatchers (Tarof et al., 2001; Watson et al., 2002; Beheler et al., 2007) in the Strangeand Sharp-tailed Tyrants, and to test the usefulness of these markers in relation to phylogenetic distance with the source species. A comprehensive study including bird species belonging to diverse orders has shown that a negative relationship exists between microsatellite cross-species amplification/polymorphism success and the genetic distance from the source species (Primmer et al., 2005), supporting what previous studies had found for smaller data sets (Primmer et al., 1996; Galbusera et al., 2000). This seems to hold for a variety of animal and plant taxa (Housley et al., 
2006; Carreras-Carbonell et al., 2008). However, how cross-species microsatellite amplification and polymorphism behave within a given bird family is not clear (Hughes et al., 1998; Dawson et al., 2005; Klein et al., 2009). Microsatellite loci have been developed for the Eastern Phoebe (Sayornis phoebe) (Watson et al., 2002; Beheler et al., 2007) and the Least Flycatcher (Empidonax minimus) (Tarof et al., 2001). Both species belong to the Contopini, a clade contained in the subfamily Fluvicolinae (Tello et al., 2009). The sister clade to the Contopini is the Fluvicolini, which contains the Alectrurus species. C. caudacuta, on the other hand, is within the subfamily Elaeniinae, which is more distantly related (Tello et al., 2009).

The knowledge on the usefulness of published microsatellite loci in such a diverse bird group that contains many species with conservation problems is very important for future studies of other Tyrant species. Moreover, microsatellite loci will allow study of the population status and reproductive aspects of the Strange- and Sharp-tailed Tyrants. Both species share the environment, inhabiting savannas, wet grasslands, and marshes in the south of Brazil, eastern Bolivia, Paraguay, and the north-east of Argentina, but little is known about their biology. Population and ecological studies on these species that expand the information on their dispersal and migration patterns, mating system, and genetic variability, among others, will be fundamental for their conservation management.

\section{MATERIAL AND METHODS}

Eighteen published primer pairs (Tarof et al., 2001; Watson et al., 2002; Beheler et al., 2007) were tested in 46 Strange-tailed Tyrant and 16 Sharp-tailed Tyrant unrelated individuals. Individuals were mist-netted between 2004 and 2009 during the reproductive (SeptemberJanuary) and non-reproductive (February-August) seasons in Reserva Ecológica El Bagual, Province of Formosa, Argentina ( $\left.26^{\circ} 18^{\prime} 17.5^{\prime \prime} \mathrm{S}, 58^{\circ} 49^{\prime} 51.1^{\prime \prime} \mathrm{W}\right)$. Before release, we took blood samples and banded all individuals with a numbered aluminum band and a combination of colored plastic rings. Blood samples ( 20 to $50 \mu \mathrm{L}$ ) were taken via wing venipuncture, immediately added to $0.5 \mathrm{~mL}$ lysis buffer (100 mM Tris, $\mathrm{pH} 8.0,10 \mathrm{mM} \mathrm{NaCl}, 100 \mathrm{mM}$ ethylenediaminetetraacetic acid, $2 \%$ sodium dodecyl sulfate), and stored at room temperature until analysis.

DNA was extracted from the blood samples with a Qiagen (Hilden, Germany) extraction kit. Polymerase chain reaction (PCR) amplifications were performed in $25-\mu \mathrm{L}$ reaction volumes using 10 to $80 \mathrm{ng}$ DNA template, $136 \mathrm{nM}$ forward and reverse primers, $0.2 \mathrm{mM}$ deoxynucleotide triphosphates, $1.5 \mathrm{mM} \mathrm{MgCl}_{2}$, and $0.5 \mathrm{U}$ Taq Polymerase (Q-BIOgene Taq Core Kit 10). To test for amplification success, we amplified DNA samples of 4 individuals of each species at 3 different annealing temperatures. When the initially tested temperatures produced multiple bands, the annealing temperatures were further increased. Reactions were cycled as follows: $5 \mathrm{~min}$ at $94^{\circ} \mathrm{C}$; then 3 cycles of $30 \mathrm{~s}$ at $94^{\circ} \mathrm{C}, 60 \mathrm{~s}$ at the annealing temperature $+3^{\circ} \mathrm{C}$, and $45 \mathrm{~s}$ at $72^{\circ} \mathrm{C}$; then 37 cycles of $30 \mathrm{~s}$ at $94^{\circ} \mathrm{C}, 60 \mathrm{~s}$ at the annealing temperature, and $45 \mathrm{~s}$ at $72^{\circ} \mathrm{C}$; and a final $10 \mathrm{~min}$ at $72^{\circ} \mathrm{C}$. PCR amplification was visualized on $2 \%$ agarose gels stained with ethidium bromide. Definitive annealing temperatures were set for those temperatures yielding the best product. Amplified products of two individuals per species were sequenced on an Applied Biosystems Model 3130xl genetic analyzer using ABI Big Dye ${ }^{\mathrm{TM}}$ terminator chemistry to check for the presence of microsatellites.

Successfully amplified primers containing microsatellites were amplified in multiplex PCRs, and tested for polymorphism with the above-mentioned sequencer. Runs were analyzed 
with GeneMapper version 3.7 (Applied Biosystems). Observed and expected heterozygosities were calculated using GenAlEx version 6 (Peakall and Smouse, 2006), and tests for HardyWeinberg disequilibrium and for departures from linkage equilibrium were conducted using a Markov chain method with Genepop version 4.0 (Rousset, 2008).

\section{RESULTS AND DISCUSSION}

Amplification success did not differ between the more closely (Strange-tailed Tyrant; $\mathrm{N}=14$ ) and more distantly (Sharp-tailed Tyrant; $\mathrm{N}=15$ ) related species to the source species (chi-square test: $\chi^{2}=0.18$, d.f. $=1, \mathrm{P}=0.67$ ). One amplifying primer set (SAP32) proved to be impossible to sequence (i.e., microsatellite contents could not be determined) because of an Arepeat near to both flanking regions, and was therefore not tested for polymorphism. Polymorphism success did not differ between the Strange-tailed Tyrant $(\mathrm{N}=9)$ and the Sharp-tailed Tyrant $(\mathrm{N}=8)\left(\chi^{2}=0.36\right.$, d.f. $\left.=1, \mathrm{P}=0.55\right)$. It is interesting to note that, except for some loci that were similarly polymorphic (SAP94, SAP104, EMIZ27, and EMID46) or monomorphic (SAP47, SAP22, and SAP96) in both species, many loci that were polymorphic for one species were reciprocally monomorphic for the other (Figure 1). This suggests that an increased phylogenetic distance does not gradually lead to allelic or locus dropouts, and that the evolution of microsatellites is undergoing distinct evolutionary pathways along different lineages.

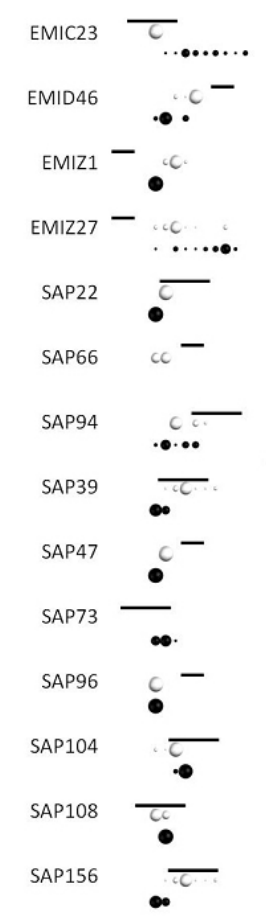

Figure 1. Alleles of loci tested for polymorphism in the Strange-tailed Tyrant (white circles) and the Sharp-tailed Tyrant (black circles). Circle size is proportional to allele frequency. The first circle represents the smallest allele, each successive circle the following one in size. Lines indicate allele size in the source species; non-overlapping lines stand for smaller or larger alleles. 
For the Strange-tailed Tyrant, two loci (SAP94 and EMIZ27) were significantly heterozygote-deficient and not in Hardy-Weinberg equilibrium $(\mathrm{P}<0.05$; Table 1$)$. Preliminary data on family groups indicate that locus SAP94 might have a high proportion of null alleles, thus leading to the observed heterozygote deficiency. Pairwise tests for linkage between the 9 polymorphic loci revealed significant genotypic linkage disequilibrium between two sets of paired loci (SAP39-SAP156 and EMIZ1-EMIZ27). For the Sharp-tailed Tyrant, all polymorphic loci were in Hardy-Weinberg equilibrium, and pairwise tests revealed significant genotypic linkage disequilibrium between two different sets of paired loci (EMIC23-EMIZ27 and EMIC23-SAP94).

\begin{tabular}{|c|c|c|c|c|c|c|c|c|c|c|}
\hline \multirow[t]{2}{*}{ Locus } & \multicolumn{5}{|c|}{ Strange-tailed Tyrant } & \multicolumn{5}{|c|}{ Sharp-tailed Tyrant } \\
\hline & $\mathrm{Ta}\left({ }^{\circ} \mathrm{C}\right)$ & $N_{\mathrm{A}}$ & Range & $H_{\mathrm{O}}$ & $H_{\mathrm{E}}$ & $\mathrm{Ta}\left({ }^{\circ} \mathrm{C}\right)$ & $N_{\mathrm{A}}$ & Range & $H_{\mathrm{O}}$ & $H_{\mathrm{E}}$ \\
\hline SAP39a & 55 & 6 & $242-260$ & 0.46 & 0.46 & 60 & 2 & $239-242$ & 0.37 & 0.43 \\
\hline SAP47 ${ }^{\mathrm{a}}$ & 50 & 1 & 261 & - & - & 50 & 1 & 251 & - & - \\
\hline SAP50a & NA & & & & & NA & & & & \\
\hline SAP73a & NA & & & & & 50 & 3 & $181-187$ & 0.47 & 0.52 \\
\hline SAP96 $6^{\mathrm{a}}$ & 60 & 1 & 162 & - & - & 60 & 1 & 162 & - & - \\
\hline SAP104a & 55 & 3 & $102-108$ & 0.15 & 0.14 & 55 & 2 & $108-110$ & 0.07 & 0.18 \\
\hline SAP108 & 60 & 2 & $201-203$ & 0.41 & 0.43 & 56.5 & 1 & 203 & - & - \\
\hline SAP156 $6^{\mathrm{a}}$ & 56.5 & 6 & $237-255$ & 0.43 & 0.43 & 56.5 & 2 & $234-237$ & 0.37 & 0.43 \\
\hline SAP22 $2^{b}$ & 56.5 & 1 & 130 & - & - & 56.5 & 1 & 122 & - & - \\
\hline SAP32b & 50 & NS & & & & 50 & NS & & & \\
\hline SAP53 $^{\mathrm{b}}$ & NA & & & & & NA & & & & \\
\hline SAP66 $6^{\mathrm{b}}$ & 55 & 2 & $142-144$ & 0.56 & 0.50 & NA & & & & \\
\hline SAP94 & 56.5 & 3 & $242-251$ & 0.11 & $0.39 * *$ & 56.5 & 5 & $236-248$ & 0.44 & 0.68 \\
\hline $\mathrm{EMIC}^{2} 3^{\mathrm{c}}$ & 55 & 1 & 291 & - & - & 55 & 9 & $307-331$ & 0.87 & 0.82 \\
\hline EMID46 ${ }^{c}$ & 55 & 3 & $346-350$ & 0.21 & 0.20 & 55 & 3 & $342-348$ & 0.44 & 0.44 \\
\hline $\mathrm{EMIZ1}^{\mathrm{c}}$ & 50 & 3 & $366-370$ & 0.43 & 0.36 & 50 & 1 & 364 & - & - \\
\hline EMIZ27 $7^{c}$ & 55 & 6 & $184-200$ & 0.46 & $0.55^{*}$ & 55 & 8 & $184-204$ & 0.69 & 0.73 \\
\hline EMI9A $^{c}$ & NA & & & & & 55 & 1 & 117 & - & - \\
\hline
\end{tabular}

$\mathrm{Ta}=$ optimal annealing temperature; $N_{\mathrm{A}}=$ number of alleles; $H_{\mathrm{O}}, H_{\mathrm{E}}=$ observed and expected heterozygozities; NA $=$ not amplified; $\mathrm{NS}=$ not sequenced. ${ }^{*}$ Hardy-Weinberg equilibrium (HWE) $\mathrm{P}<0.05 .{ }^{*} *$ HWE $\mathrm{P}<0.001 .{ }^{a}$ Beheler et al., 2007; ' Watson et al., 2002; 'Tarof et al., 2001.

Previous studies have shown that locus variability is positively associated with repeat number (Primmer et al., 2005; Küpper et al., 2008; but see Karaiskou et al., 2008). However, when considering the repeat number and the polymorphism of the loci in the source species (Tarof et al., 2001; Watson et al., 2002; Beheler et al., 2007), such association was not evident (Spearman rank: $\mathrm{R}=0.22, \mathrm{P}=0.36$ ). Furthermore, polymorphism of the loci in our species studied was not significantly correlated with repeat number in the source species (Strangetailed Tyrant: $\mathrm{R}=0.12, \mathrm{P}=0.62$; Sharp-tailed Tyrant: $\mathrm{R}=0.21, \mathrm{P}=0.40$ ). Many loci with a high number of repeats in the source species failed to amplify, whereas others with a low repeat number showed to be highly polymorphic in our species.

Our results show that the more general patterns of microsatellite evolution found in birds (Primmer et al., 2005) are not exhibited in Tyrant flycatchers. This might be related to the inclusiveness of the studies, since we only focused on one particular family (Tyrannidae), whereas previous studies included species belonging to several bird families and orders. Flanking regions are probably more conserved within a family, thus precluding amplification failure (Küpper et al., 2008). However, Dawson et al. (2005) found higher chances of amplifying the 
isolated loci in auklets (Aves: Laridae) species belonging to the same subfamily as the source species than in species belonging to a different subfamily. Thus, there does not seem to be a generalized pattern of microsatellite evolution in birds. Loci variation is probably related to their location in the genome (Karaiskou et al., 2008), where they can be subject to different selective pressures, as well as to the divergence time between species, which can be very variable among different clades. It is, thus, recommendable to test for all the available published primers for one bird family, without discarding them on the basis of phylogenetic distance, polymorphism, or repeat number. In particular, for the Tyrant flycatchers, where several species have conservation problems, all 18 published primers should be tested for each single species.

\section{ACKNOWLEDGMENTS}

We are grateful to the Deutscher Akademischer Austauschdienst (DAAD), Consejo Nacional de Investigaciones Científicas y Técnicas (CONICET), and Agencia Nacional de Promoción Científica y Tecnológica (PICT \#2008-1599) for financial support. B. Mahler, A.S. Di Giacomo, and J.C. Reboreda are recipients of research fellowships from CONICET. We also thank Alparamis S.A. and Aves Argentinas/Asociación Ornitológica del Plata for allowing us to conduct part of this study at Reserva El Bagual, and K. Havenstein for laboratory support.

\section{REFERENCES}

Beheler AS, Fike JA and Rhodes OE Jr (2007). Eight new polymorphic microsatellite loci from the eastern phoebe (Sayornis phoebe). Conserv. Genet. 8: 1259-1261.

Bird Conservation International (2009). IUCN Red List for Birds. Available at [http://www.birdlife.org]. Accessed July 20, 2012.

Carreras-Carbonell J, Macpherson E and Pascual M (2008). Utility of pairwise mtDNA genetic distances for predicting cross-species microsatellite amplification and polymorphism success in fishes. Conserv. Genet. 9: 181-190.

Dawson DA, Hunter FM, Pandhal J, Buckland R, et al. (2005). Assessment of 17 new whiskered auklet (Aethia pygmaea) microsatellite loci in 42 seabirds identifies 5-15 polymorphic markers for each of nine Alcinae species. Mol. Ecol. Notes 5: 289-297.

Devenish C, Díaz Fernández DF, Clay RP, Davidson I, et al. (2009). Important Bird Areas Americas: Priority Sites for Biodiversity Conservation. BirdLife Conservation Series No. 16. BirdLife International, Quito.

Fitzpatrick JW (2004). Family Tyrannidae (Tyrant-flycatchers). In: Handbook of the Birds of the World. Vol. 9. Cotingas to Pipits and Wagtails (del Hoyo J, Elliot A, Christie DA, eds.) Lynx Edicions, Barcelona, 170-462.

Galbusera P, van Dongen S and Matthysen E (2000). Cross-species amplification of microsatellite primers in passerine birds. Cons. Genet. 1: 163-168.

Housley DJ, Zalewski ZA, Beckett SE and Venta PJ (2006). Design factors that influence PCR amplification success of cross-species primers among 1147 mammalian primer pairs. BMC Genomics 7: 253.

Hughes CR, Kavlie R and Johnson K (1998). Characterization of polymorphic trinucleotide microsatellite loci in the greattailed grackle, Quiscalus mexicanus. Mol. Ecol. 7: 783-784.

Karaiskou N, Buggiotti L, Leder E and Primmer CR (2008). High degree of transferability of 86 newly developed zebra finch EST-linked microsatellite markers in 8 bird species. J. Hered. 99: 688-693.

Klein A, Horsburgh GJ, Küpper C, Major A, et al. (2009). Microsatellite markers characterized in the barn owl (Tyto alba) and of high utility in other owls (Strigiformes: AVES). Mol. Ecol. Resour. 9: 1512-1519.

Küpper C, Burke T, Székely T and Dawson DA (2008). Enhanced cross-species utility of conserved microsatellite markers in shorebirds. BMC Genomics 9: 502.

Ohlson JI, Fjeldså J and Ericson PGP (2008). Tyrant flycatchers coming out in the open: phylogeny and ecological radiation of Tyrannidae (Aves, Passeriformes). Zool. Scripta 37: 315-335.

Peakall R and Smouse PE (2006). GENALEX 6: Genetic analysis in Excel. Population genetic software for teaching and research. Mol. Ecol. Notes 6: 288-295.

Primmer CR, Painter JN, Koskinen MT, Palo JU, et al. (2005). Factors affecting avian cross-species microsatellite 
amplification. J. Avian Biol. 36: 348-360.

Primmer CR, Moller AP and Ellegren H (1996). A wide-range survey of cross-species microsatellite amplification in birds. Mol. Ecol. 5: 365-378.

Rousset F (2008). Genepop'007: a complete reimplementation of the Genepop software for Windows and Linux. Mol. Ecol. Resour. 8: 103-106.

Tarof SA, Ratcliffe LM and Boag PT (2001). Polymorphic microsatellite loci for assigning parentage in least flycatchers (Empidonax minimus). Mol. Ecol. Notes 1: 146-148.

Tello JG, Moyle RG, Marchese DJ and Cracraft J (2009). Phylogeny and phylogenetic classification of the tyrant flycatchers, cotingas, manakins, and their allies (Aves: Tyrannides). Cladistics 25: 429-467.

Watson CJW, Beheler AS and Rhodes OE Jr (2002). Development of hypervariable microsatellite loci for use in eastern phoebes (Sayornis phoebe) and related Tyrannids. Mol. Ecol. Notes 2: 117-118. 